\title{
From the Editor: A Personal Coda
}

\author{
THOMASINE KUSHNER
}

The Cambridge Consortium for Bioethics Education took place at the Cambridge University Press offices in New York this April. Hosted and sponsored by the Press, with cosponsors, CQ and the Program in Medicine \& Human Values at California Pacific Medical Center in San Francisco, the Consortium brought together representative leaders in bioethics to discuss some of the unsolved issues in the field: goals, curriculum, methods, and assessment. For three days participants shared their own programs, research, and current projects as well as ideas on where bioethics education needs to go in the future. Beginning with this special section, and in CQ's Bioethics Education section in subsequent volumes, we will be bringing you what is happening as bioethicists everywhere take a more focused approach to the field.

Hearing other people's experiences at the Consortium prompted me to take a backward look at my own life in bioethics education beginning in 1983 when, as a faculty member in the philosophy department of a local university, Donald Buckner, Chief of Pediatric Surgery at the University of Miami School of Medicine, and I initiated something we called "Ethics Rounds" in his Pediatric Intensive Care Unit. Residents followed Don as we moved from one tiny patient to another, he discussing not only the medical facts but in each instance equally addressing the ethical concerns. His residents learned early on that there are always ethical issues, along with the powerful message that one of the institution's most revered physicians recognized them as integral to treating the patient-not universally accepted in those early years.

During that period, I also taught a section on bioethics to the 125 freshman medical students. It was a large amphitheater, and it was a tough audience. Students were eager to get on with "real" medicine and, with few exceptions, had little interest in what they viewed as extraneous material. One lecture, while I fascinated myself explicating "Killing and Letting Die" arguments, I spied a young man sitting in the highest most removed bleacher section of the auditorium reading a newspaper. He taught me an important lesson that changed my whole approach to bioethics education: it's not about theory, it's about life. (Wherever you are now, I thank you.)

I took that lesson with me when I went to Berkeley to teach bioethics in the UCB-UCSF Joint Medical Program. Here, rather than lectures, the class was constituted as an ethics committee, and each session, chairs from hospital ethics committees from around the Bay Area came and presented a real case that had come before their committee. In preparation, the week before students received the case in the form of a referral, along with pertinent articles from the literature. 
In class, the mock committee members discussed, debated, and challenged each other's positions and, in the end, made their recommendations. The class was greatly enriched by students from other disciplines who enrolled in the class. For example, law students could always be counted on for lively discussion, and, if three future lawyers were in attendance, there were at least four opinions. Afterward, when the visiting chair told them "what really happened," it was often apparent that the students had matched the real committee's performance.

For over a dozen years this "Ethics Committees at Work" class was one of the program's most popular courses, but a letter from a former student taught me another lesson that this was not enough. Now in his clinical training, he said that as much as he gained from class with respect to grappling with traditional bioethics topics, he found himself unprepared to deal with a new set of issues. He wrote, "No one addresses the problems of working in a power hierarchy. We are bottom feeders and we don't know how to handle it." In reaching out to other doctors in training, they told me the kind of help they were looking for: How can I maintain my own integrity and at the same time protect myself from negative repercussions? At what point do I go around a superior "who knows best" when I seriously question his or her ethical behavior? What methods should I use to act on my convictions in a way that is effective and constructive? Ward Ethics, coauthored with David Thomasma, a series of real-life experiences from trainees around the world along with responses from ethicists and clinicians, came about as a response to their questions. The column, "What Do I Do Now?" that ran for a year in the British Medical Journal's student publication responded in similar fashion to questions submitted by medical trainees around the United Kingdom.

The landmarks from my own journey in bioethics education clearly read "more life and less theory" — not an easy lesson for a philosopher. Currently, I am at work on developing a series of rounds for residents on the "What Do I Do Now?" model where physicians, both senior faculty and trainees, break the traditional "code of silence" that often prevents open discussion of the very experiences and dilemmas trainees find most disturbing. As one of the senior physician faculty members acknowledges:

There is a sense that it is not "professional" to air our dirty laundry, and to call attention to issues that have not been addressed makes everyone uncomfortable. We are willing to talk about patient problems, but we are reluctant to open up discussions involving our own gaps in education and problems in relationships. To talk about the glitches and the screwups would be to admit that we are not as perfect as we are trying to portray ourselves to be.

I'll keep you posted on how it goes. 